$\sqrt{10} 00$

\section{Reconstrucciones históricas del patrimonio}

Ana Robles Anaya

Técnica documentalista. Escuela Taller "Poblado Nazari"

Las reconstrucciones y ambientaciones históricas -técnicas interpretativas del patrimonio ${ }^{1}$ - siempre han dado lugar a debate; bien por el peligro que supone el exceso de patrimonialización que la sociedad actual preconiza y la consecuente pérdida de valor que esto supone, bien por una inadecuada gestión que prioriza el escaparatismo y el enriquecimiento económico, situando al patrimonio como un objeto más de uso y consumo, sin premisas de calidad y ética profesional. Sin embargo, de todos es sabido, que el patrimonio constituye un recurso cultural de gran potencial generador de renta y trabajo- para el desarrollo de muchas comunidades locales.

Actualmente, a nivel europeo, existen proyectos que suponen una apuesta por el patrimonio, dan respuesta a necesidades sociales de conservación y difusión patrimonial, saben conjugar fórmulas novedosas de interpretación, educación, investigación, cultura y ocio, crean empleo estable y colaboran en el desarrollo rural y local sostenibles. Se trata de ofertas educativas, lúdicas y vivenciales basadas en la experimentación científica y la difusión del patrimonio, con amplia proyección social y turística.

Las fórmulas empleadas son muy variopintas; van desde la creación de ecomuseos, que ilustran y recuperan la historia y la identidad de los lugares que representan, pasando por reconstrucciones históricas con objetivos comerciales para financiar otro tipo de actividades patrimoniales -excavaciones arqueológicas e investigaciones científicas- o aquéllas que nacen con el impulso de profundizar en una determinada etapa o periodo histórico y revitalizar zonas rurales.

Dentro de la primera línea de trabajo expuesta, destacan iniciativas como la llevada a cabo por el Beamish Open Air Museum (Durham, Reino Unido), que responde a la necesidad de evitar la dispersión de la identidad regional tras la pérdida, en 1958, de la vieja industria minera. El museo, inaugurado en 1970, ilustra el modo de vida de principios de los siglos XIX y XX. Los fondos se han conformado a través de donaciones privadas, la recuperación de una mina y una granja y varios edificios traídos de todas partes de la región. Beamish constituye una las principales atracciones turísticas del norte de Inglaterra. Se autofinancia en un $96 \%$ gracias a la venta de entradas, los ingresos de la tienda, la restauración, los alquileres de espacios, las esponsorizaciones y la celebración de eventos especiales. Cuenta, además, con un amplio número de voluntarios y amigos del museo, que junto a un extenso equipo de profesionales e intérpretes, llevan a cabo numerosas actividades didácticas, con inclusión de teatralizaciones y experiencias de living history, que nos sumergen en el modo de vida victoriano.

Subrayamos también la labor realizada por diversos entornos mineros que han apostado por un ambicioso plan de conservación y puesta en valor de sus minas, para evitar la pérdida de identidad y del patrimonio cultural industrial. Este es el caso de Scopriminiera (Prali, Piamonte, Italia), Ironbridge (Reino Unido) y el Parque Minero de Riotinto (Huelva, España). En todos los ejemplos, los trabajos de documentación e investigación científica ocupan un lugar esencial. La amplia gama de experiencias de aprendizaje que se ofertan -visita a las minas y lugares de extracción, zonas arqueológicas, entornos naturales, monumentos históricos o bienes de interés etnográfico- facilita la comprensión cultural de la industria minera y la siderurgia, provee nuevas formas de ocupación y satisface la demanda cultural, turística y emocional de los visitantes.

Un claro ejemplo de ambientación histórica con objetivo comercial es el protagonizado por Jorvik (York, Reino Unido), una atracción completamente moderna en la que se recrea el original poblado vikingo excavado bajo la ciudad de York. A través de los ingresos proporcionados por las visitas y las numerosas actividades didácticas que se imparten, se promueve la continuidad de las excavaciones en el yacimiento original y la labor investigadora de numerosos arqueólogos y especialistas que trabajan en el proyecto.

Finalmente, destacamos varios ejemplos de reconstrucciones históricas para la comprensión de una determinada etapa o período histórico. Todos tienen en común que se desarrollan en espacios naturales con fines sociales, logrando la participación directa de los ciudadanos y las comunidades locales en las que se inser$\tan ^{2}$, basan su ejecución en un amplio estudio documental, la toma de decisiones se desarrolla a través de un comité científico especializado y potencian la inmersión psicológica y física, a través de la amplia gama de experiencias recreativas, emocionales e intelectuales que ofertan.

Guédelon (Puisaye, Francia) es un proyecto turístico y pedagógico que ha recibido numerosas menciones y premios. Aparece como una obra permanente y evolutiva en la que un grupo de cuarenta y cinco obreros construye un castillo utilizando las técnicas del siglo XIII. Todo se realiza ante la atenta mirada de sus visitantes que observan el proceso constructivo y redescubren la riqueza de diferentes oficios artesanales participando en diferentes talleres.

La Prehistoria aparece representada en su etapa calcolítica y en la edad del Hierro en el Centro Algaba (Ronda, Málaga, España) y el Poblado Cántabro, (Argüeso, Cantabria, España) respectivamente. Ambos espacios presentan reconstrucciones históricas científicas, fieles a las técnicas y materiales de época, a partir de un interesante trabajo de arqueoexperimentación. En el caso del Centro Algaba, se ofrecen además programas de educación ambiental, agroecología -aprovechamiento agroforestal- agricultura y ganadería ecológica -recuperación de razas autóctonas bovinas andaluzas ganaderas, en peligro de extinción- 


\section{Opinión del lector}

Santos M. Mateos Rusillo

Experto en comunicación del patrimonio. U. de Vic

Finalmente, destacamos el proyecto Poblado Nazarí (Cortes de la Frontera, Málaga), una iniciativa cultural cuya propuesta consiste en la creación de un pequeño asentamiento rural de época nazarí utilizando para ello los materiales, las herramientas y la tecnología propia de esta etapa histórica. A pesar de que el proyecto se encuentra en un estado embrionario, Poblado Nazari ofrecerá una información comprehensiva de su contexto cultural, dando lugar a múltiples lecturas -la historia, la agricultura, la alimentación, los oficios manuales,...-, una visión de conjunto que, para un público no especializado, es muy difícil de obtener mediante métodos e instrumentos de formación-presentación convencionales. Para reforzar su rigor científico, se está elaborando un importante fondo documental y se ha constituido un grupo asesor compuesto por expertos y expertas en diferentes materias de la vida cotidiana de la Andalucia rural del siglo XV. Ellos se encargan de validar sus contenidos y de prestigiar el proyecto con su presencia. La puesta en marcha del proyecto se ha realizado a través de la Escuela Taller Poblado Nazarí -inicio en abril de 2005-, plan de formación dirigido a capacitar profesionalmente a un grupo de jóvenes de la comarca para la futura gestión del Centro, al mismo tiempo que se favorece el desarrollo personal y la superación individual de cada uno de ellos.

Notas

${ }^{1}$ “La interpretación facilita la presentación y el uso social del patrimonio, y permite ofrecer diferentes lecturas y opciones para un uso activo del patrimonio empleando para ello toda clase de recursos y dispositivos de presentación y animación". BALLART HERNÁNDEZ, J JUAN I TRESSERRAS, J. (2005) Gestión del Patrimonio Cultural. Barcelona: Arial, 2005.

${ }^{2}$ “No se puede plantear la interpretación del patrimonio de espaldas a los intereses y voluntades de la población. La implicación de la comunidad es necesaria ya que en muchos casos la población local no se siente identificada con proyectos en los que no ha participado". BALLART HERNÁNDEZ, J; JUAN I TRESSERRAS, J. (2005) Gestión del Patrimonio Cultural. Barcelona: Arial, 2005

Sitios web:

$>$ Beamish (www.beamish.org.uk; www.beamishcollections.com)

$>$ Scopriminiera (www.scopriminiera.it)

$>$ Ironbridge (www.ironbridge.org.uk)

$>$ Parque minero de Riotinto (parquemineroderiotinto.sigadel.com)

$>$ Jorvik (www.vikingjorvik.com)

$>$ Guédelon (www.guedelon.com)

> Poblado Cántabro (www.pobladocantabro.com)

$>$ Centro Algaba (www.algabaderonda.com)
Como toda creación cultural, y, por tanto, en constante evolución, estamos asistiendo de unos años a esta parte al creciente éxito del patrimonio cultural como recurso económico, directamente relacionado con el emergente turismo cultural, actividad productiva asociada a la industria cultural cuyo objetivo fundamental es la generación de beneficios. Lo que no necesariamente supone una asociación negativa, si en ese proceso de transformación del recurso en servicio o producto se tienen en cuenta las singularidades de la materia prima con la que se trabaja, y se revierten parte de los beneficios en su mejor conocimiento y conservación.

En cierta manera es injusta la relación que normalmente se establece entre democratización del acceso a los recursos patrimoniales y trivialización o pasteurización cultural, pues parte de posiciones apocalipticas que continúan tildando peyorativamente a la divulgación como sucedáneo negativo del conocimiento cientifico. Postura elitista que desde su torre de marfil olvida totalmente al usuario final y negativiza apriorísticamente la democratización (por otra parte utópica) del acceso al conjunto de bienes culturales.

Nuestra postura hace depender todas las consideraciones del resultado final para con el patrimonio y la sociedad. Porque en este tema, tan importante es el uno como la otra. Si el resultado final es respetuoso (físicamente) con el recurso y se comunica (conceptualmente) mediante un discurso divulgativo bien ejecutado (basado en técnicas de comunicación que facilitan disciplinas como la Interpretación y la Didáctica), se conseguirá un servicio enriquecedor para la sociedad (tanto intelectual como económicamente) del que, finalmente, se beneficia el propio patrimonio. En este sentido, y siguiendo al semiólogo italiano Umberto Eco, nuestra postura es totalmente integrada, al aceptar la inclusión del patrimonio en la industria cultural si ésta cumple con toda una serie de condicionantes inherentes a una materia prima como la nuestra. Porque, al fin y al cabo, esta relación de intereses es la que en buena medida permitirá la supervivencia física y conceptual de nuestros bienes culturales.

Los gestores y profesionales del patrimonio deberiamos aceptar y participar activamente en su inclusión en la esfera económica, pues será lo que finalmente posibilite su uso social con garantías. Uso (que no abuso) social sin el cual, sinceramente, no tienen mucho sentido los esfuerzos en investigación, documentación o conservación. Obviamente, siempre y cuando se trabaje para conseguir un resultado final de calidad que parta obligatoriamente del conocimiento $y$ del respeto hacia un recurso frágil como es nuestro patrimonio cultural. 